\title{
Age and growth of the ommastrephid squid Todarodes sagittatus from the western Mediterranean Sea
}

\author{
Antoni Quetglas* ${ }^{\ddagger}$ and Beatriz Morales-Nin ${ }^{\dagger}$ \\ *IEO, Centre Oceanogràfic de Balears, Apt. 291, E-07015 Palma de Mallorca, Spain. \\ ${ }^{\dagger}$ CSIC/UIB-IMEDEA, Miguel Marqués 21, E-97190 Esporles, Illes Balears, Spain. \\ ${ }^{\ddagger}$ Corresponding author, e-mail: quetglas@ba.ieo.es
}

\begin{abstract}
Age and growth of Todarodes sagittatus were estimated based on statolith analysis from individuals $(\mathrm{N}=352$; 81-418 mm mantle length) caught by bottom trawlers during a year of sampling in the western Mediterranean. The daily nature of statolith increments was indirectly validated comparing the mean age of consecutive monthly modes (identified on the monthly length-frequency distributions) with the corresponding increase of 30 days. In agreement with other ommastrephids, results confirmed the following points: (1) lifespan lasts nearly a year; (2) growth rates decrease with age; (3) when adult, females have higher growth rates than males; and (4) females mature about a month later than males. Significant correlation was found between hatching (which occurred throughout the year but with a peak in November) and temperature at $50 \mathrm{~m}$ depth (where it is thought that hatchlings inhabit). Age and growth results were compared with those obtained in a similar work carried out in north-west Africa (Arkhipkin et al., 1999). Comparisons suggested that due to higher growth rates in juveniles, southern populations reach maturity and consequently decrease somatic growth at younger ages and smaller sizes than northern squid, which attain larger sizes as a result of maintaining fast growth and delaying maturation. Greater growth rates in juveniles from west Sahara could be explained by higher temperatures in this area than in the Mediterranean.
\end{abstract}

\section{INTRODUCTION}

The European flying squid Todarodes sagittatus (Lamarck, 1798) is an oceanic species occurring in the east Atlantic from Guinea to the Arctic Ocean and also in the Mediterranean Sea. The species inhabits the shelf and continental slope, making diel vertical movements between the surface at night and near the bottom during daytime. The squid has been well studied in the North Atlantic, where populations carry out an autumn feeding migration from spawning areas in the Azores Islands and southern Ireland to fishing grounds in Norwegian waters (Wiborg \& Gjosaeter, 1981; Wiborg et al., 1982; Borges \& Wallace, 1993). However, the studies developed in this area are limited to immature squid because the majority of individuals undertaking this migration are juveniles. There is no evidence of large displacements in west African and Mediterranean populations, where only ontogenetic bathymetric movements have been reported (Quetglas et al., 1998; Arkhipkin et al., 1999).

The age and growth of $T$. sagittatus have been studied in the Atlantic, both in northern and southern populations, but never in the Mediterranean Sea. Growth rate estimates based both on length-frequency distributions (Jonsson, 1980; Wiborg, 1980; Borges \& Wallace, 1993) and statolith analysis (Rosenberg et al., 1980; Shimko, 1984; Lordan et al., 2001) gave similar results, which ranged from 0.5 to $2 \mathrm{~mm} \mathrm{~d}^{-1}$. However, detailed comparisons of these values are not possible because they were obtained for the population as a whole. Among other factors (mainly temperature and food intake), growth rates vary greatly with age and the only study analysing the growth during ontogenetic development in both sexes was carried out from west Saharan populations (Arkhipkin et al., 1999). In the present paper, we also analyse the evolution of growth with age and make detailed comparisons of our results from the Mediterranean with those obtained in north-west Africa.

Statolith ageing methods suggest that the lifespan of T. sagittatus lasts approximately one year, although some large individuals from the North Atlantic could live up to 1.5 years (Rosenberg et al., 1980; Wiborg \& Gjosaeter, 1981; Lordan et al., 2001). However, to date daily increment counts on statoliths have not been validated in the species and daily deposition is assumed.

In the Mediterranean Sea T. sagittatus has a low commercial value, being caught as a by-catch by bottom trawlers fishing for the red shrimp and hake (Quetglas et al., 1998). Although mature individuals are found all the year round, there is a peak from September to December. Spawning seems to take place in deep waters because all mature females were found deeper than $500 \mathrm{~m}$. In this paper the age and growth of T. sagittatus based on microstructural examination of statoliths are analysed for the first time in the Mediterranean.

\section{MATERIALS AND METHODS}

$$
\text { Squid sampling }
$$

Individuals were collected monthly from August 1995 to August 1996 on-board commercial trawlers from Mallorca (Balearic Islands, western Mediterranean). All the hauls were performed from 50 to $800 \mathrm{~m}$ depth during daytime hours (from 0800 to 1600 hours).

Mantle length (ML, to the nearest $\mathrm{mm}$ ), total weight ( $\mathrm{TW}$, to the nearest $0.1 \mathrm{~g}$ ), sex and maturity stage (immature, maturing and mature; see Quetglas et al., 1998) were measured on fresh squid in the laboratory. Both statoliths 
were removed from each individual and preserved in 96\% ethyl alcohol.

In order to determine the influence of gonad development and feeding on growth, the nidamental gland length (NGL, to the nearest $\mathrm{mm}$ ), gonad weight (GW) and digestive gland weight (DGW) were also taken (to the nearest $0.01 \mathrm{~g}$ ).

\section{Statolith sampling and processing}

Whenever possible the right statolith was used for age determination. Statolith length (SL), was measured to the nearest $\mu \mathrm{m}$ using a binocular microscope $(40 \times)$ and a camera lucida. Statoliths were prepared as described by Villanueva (1992). Statoliths were placed concave-side up on a slide under a binocular dissecting microscope, covered with a drop of Protexx resin and allowed to dry overnight. The statoliths were then polished using $3 \mathrm{M}$ commercial waterproof sandpaper of $30 \mu \mathrm{m}$ for grinding and $1 \mu \mathrm{m}$ for fine polishing until the nucleus appeared. The Protexx resin was then removed by submerging the slide in acetone and the procedure was performed on the convex side. Growth increments were counted using an image analysis system from the first visible ring, adjacent to the nucleus, to the edge of the dorsal dome or to the rostrum, depending on the grinding plane. Increments in the outermost portion of the dorsal dome were obliterated in most of the prepared statoliths, being consequently estimated by extrapolation whenever this area was smaller than $10 \%$ of the total increment width.

In order to confirm the consistency in ageing (verification), two replicate counts were obtained by the first author for statoliths of 20 squid (two individuals in each $50 \mathrm{~mm}$ interval from 100 to $400 \mathrm{~mm} \mathrm{ML}$ ). The coefficient of variation (CV) (Chang, 1982) was calculated to determine the degree of consistency:

$C V=100 \cdot \sqrt{\frac{\sum_{i=1}^{R}\left(X_{i j}-\bar{X}_{j}\right)^{2} /(R-1)}{\bar{X}_{j}}}$

where $X_{i j}$ is the $i$ th age estimation of the $j$ th squid, $\bar{X}_{j}$ is the mean age of the $j$ th squid, and $R$ is the number of times each squid is aged. Maximum $\mathrm{CV}$ value of $5 \%$ is the limit for acceptable readings (Laine et al., 1991).

The daily nature of statolith increments was indirectly validated by comparing the difference between mean ages of consecutive monthly modes with the 30 days elapsed between modes. Only modal sizes of males from February to July were analysed because this is the period during which growth is most notable (see Quetglas et al., 1998). Comparisons were tested using the $\chi^{2}$-test.

\section{Data treatment}

Analysis of covariance (ANCOVA) was used to determine whether significant differences existed in growth curves (the log-transformed power function was always used) for males and females (Sokal \& Rohlf, 1995). The Age-ML, Age-TW and ML-SL relationships were calculated using the function or functions that better fitted the data. Daily growth rates (DGR, $\mathrm{mmd}^{-1}$ or $\left.\mathrm{g} \cdot \mathrm{d}^{-1}\right)$ and instantaneous daily growth rates $(\mathrm{G}$, percentage of ML or TW) were calculated for each 30 days interval using the equations given by Forsythe \& Van Heukelem (1987):

$\operatorname{DGR}=\left(\mathrm{Y}_{2}-\mathrm{Y}_{1}\right) /\left(\mathrm{t}_{2}-\mathrm{t}_{1}\right)$ and

$\mathrm{G}=100 \cdot\left(\ln \mathrm{Y}_{2}-\ln \mathrm{Y}_{1}\right) /\left(\mathrm{t}_{2}-\mathrm{t}_{1}\right)$

where $\mathrm{Y}_{1}$ is the ML or TW at age $\mathrm{t}_{1}$. The nidamental gland index $(\mathrm{NDI}=100 \cdot \mathrm{NDL} / \mathrm{ML})$, gonadosomatic index $(\mathrm{GSI}=100 \cdot \mathrm{GW} / \mathrm{TW})$ and digestive gland index (DGI $=100 \cdot \mathrm{DGW} / \mathrm{TW}$ ) were also determined for each $30 \mathrm{~d}$ interval.

The age at which $50 \%$ of the population individuals were mature was determined fitting a sigmoidal curve to the data. The hatching date of each individual was estimated by back-calculation from the date of capture based on the number of statolith increments counted. To analyse the influence of temperature on hatching, monthly data at $50 \mathrm{~m}$ depth (where hatchlings inhabit: Watanabe, 1965; Shimko, 1989; Sakurai et al., 1996) were obtained throughout the year of sampling (Fernández de Puelles, personal communication). The correlation coefficient (Sokal \& Rohlf, 1995) between temperature and the number of hatchlings was calculated.

In order to compare our results with those obtained by Arkhipkin et al. (1999) in north-west Africa, the mean ML and TW (obtained using the Gompertz growth function given by these authors) along with the G and DGR from this population were calculated for the same 30-d age intervals we used. As individuals analysed in west Sahara were always younger than $270 \mathrm{~d}$ old, values from this age are only extrapolations.

\section{RESULTS}

\section{Age determination and validation}

A total of 352 squids (155 males and 197 females) were analysed, ranging from 81 to $307 \mathrm{~mm} \mathrm{ML}$ in males and from 118 to $418 \mathrm{~mm}$ ML in females. The statoliths showed clear growth increments in most of the preparations $(96.2 \%$ of polished statoliths interpretable). The $\mathrm{CV}$ index ranged between $0.46 \%$ and $3.55 \%$ showing that

Table 1. Growth curves of Todarodes sagittatus from the western Mediterranean Sea. ML, mantle length, TW, total weight; Age, number of increments (days) in statoliths.

\begin{tabular}{lllll}
\hline Model & Males $(\mathrm{N}=155)$ & $r^{2}$ & Females $(\mathrm{N}=197)$ & $r^{2}$ \\
\hline Power function & $\mathrm{ML}=0.359 \cdot \mathrm{Age}^{1.171}$ & 0.878 & $\mathrm{ML}=0.304 \cdot$ Age $^{1.224}$ & 0.903 \\
Linear function & $\mathrm{ML}=1.035 \cdot \mathrm{Age}^{-26.927}$ & 0.861 & $\mathrm{ML}=1.296 \cdot$ Age $^{-57.529}$ & 0.907 \\
Exponential function & $\mathrm{TW}=4.131 \cdot \mathrm{e}^{0.018 \text { Age }}$ & 0.844 & $\mathrm{TW}=5.253 \cdot \mathrm{e}^{0.018 \mathrm{Age}}$ & 0.908 \\
Power function & $\mathrm{TW}=3 \cdot 10^{-7} \mathrm{Age}^{3.801}$ & 0.867 & $\mathrm{TW}=8 \cdot 10^{-8}$ Age $^{4.086}$ & 0.904 \\
\hline
\end{tabular}



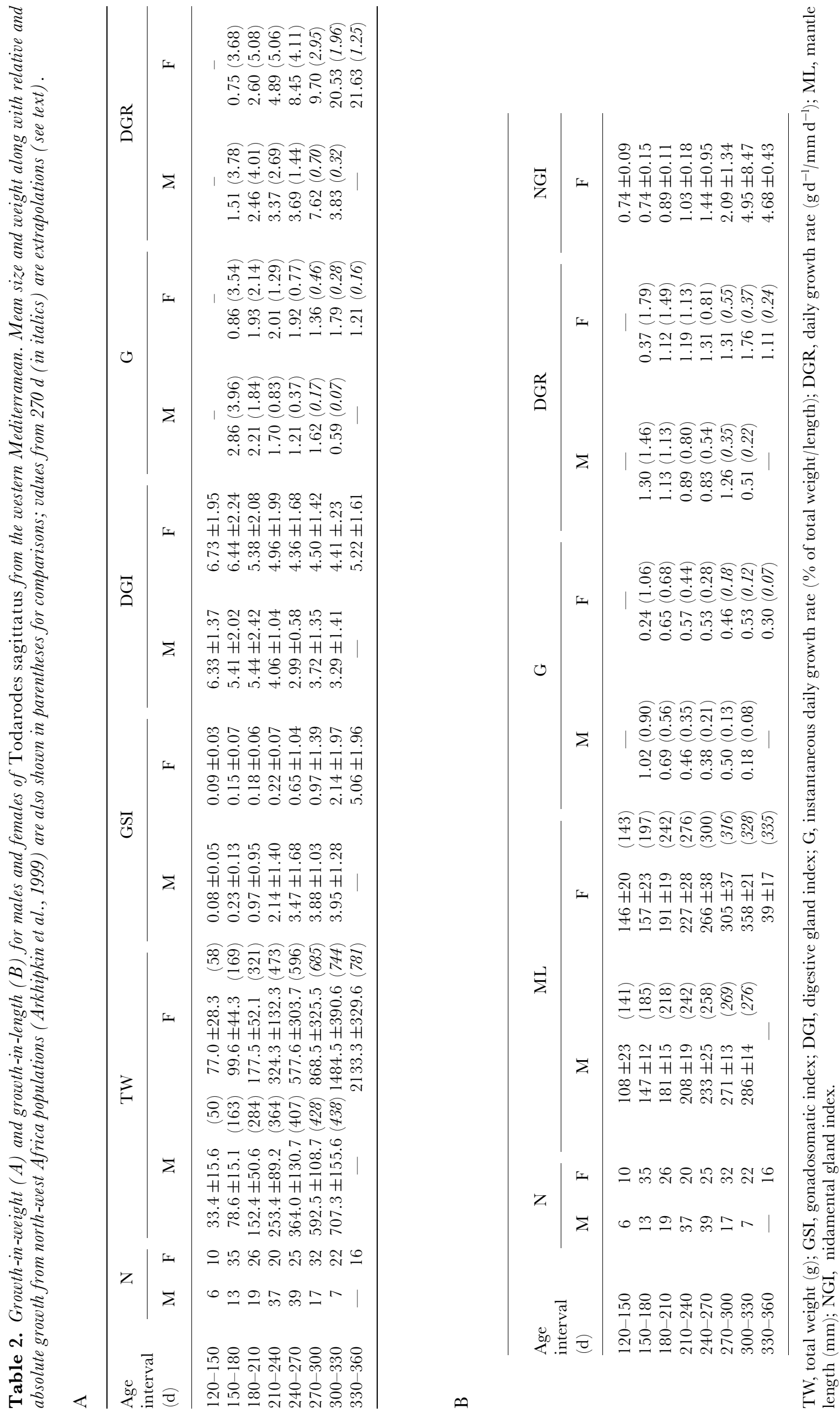
the increment interpretation was consistent. Differences between mean ages of consecutive modes were not significantly different $\left(\chi^{2}\right.$-test, $\left.P>0.05\right)$ from the corresponding 30 days (February-March: 22d; March-April: 29d; April-May: 29d; May-June: $24 \mathrm{~d}$; June-July: $29 \mathrm{~d}$ ). Another indirect validation of the daily periodicity of the increment formation could be the coincidence between the reproductive period (September-December, Quetglas et al., 1998) and the peak of back-calculated hatching dates (November, see below). Thus, the increments are considered to be laid down with daily periodicity and valid for age determination. The number of increments may not exactly represent the age in days because the interval between hatching and first increment deposition is not known. However, the error is considered negligible since it is generally recognized that the first increment is formed upon hatching in ommastrephids (Lipinski et al., 1991; Arkhipkin \& Golub, 2000).

\section{Growth and age-related parameters of squid}

Statolith length ranged between $807 \mu \mathrm{m}(80 \mathrm{~mm} \mathrm{ML}$, $13 \mathrm{~g} \mathrm{TW})$ and $2188 \mu \mathrm{m}$ (290 mm ML, $882 \mathrm{~g} \mathrm{TW})$ in males, and between $1074 \mu \mathrm{m}$ (144 mm ML, $64 \mathrm{~g} \mathrm{TW})$ and $2626 \mu \mathrm{m}$ (418 mm ML, $2740 \mathrm{~g}$ TW) in females. The MLSL relationships were well described by the linear and power equations:

$$
\begin{aligned}
\text { Males: } \mathrm{SL} & =0.0050 \mathrm{ML}+0.508, r^{2}=0.757 \\
\mathrm{SL} & =0.057 \mathrm{ML}^{0.622}, r^{2}=0.756, \mathrm{~N}=145
\end{aligned}
$$

Females: $\mathrm{SL}=0.0043 \mathrm{ML}+0.687, r^{2}=0.845$;

$$
\mathrm{SL}=0.062 \mathrm{ML}^{0.608}, r^{2}=0.831, \mathrm{~N}=192
$$

Statolith growth was allometrically negative $(P<0.001)$ and showed sexual dimorphism because, although slopes were not significantly different $\left(F_{1,320}=0.4, P>0.05\right)$, intercepts were $\left(F_{1,321}=4.7, P<0.05\right)$.

The youngest male $(80 \mathrm{~mm} \mathrm{ML}, 13 \mathrm{~g}$ TW) and female (148 mm ML, 77.2 g TW) were 122 and 136 days old, respectively. The oldest female $(411 \mathrm{~mm} \mathrm{ML}, 2413 \mathrm{~g}$ TW, $354 \mathrm{~d}$ ) was more than a month older than the oldest male (282 mm ML, 606.5 g TW, $314 \mathrm{~d}$ ).

The Age-ML relationship was well described by the power and linear equations while the Age-TW relationship was well fitted by the power and exponential equations (Table 1). The ANCOVA results showed significant differences between sexes both in growth-in-length $\left(F_{1,321}=119, P<0.0001\right)$ and growth-in-weight $\left(F_{1,321}=101\right.$, $P<0.0001)$. Males had lower $r^{2}$ values than females, reflecting greater variability in growth rates. The growthin-length and growth-in-weight were allometrically positive since slopes were significantly higher than 1 and 3 , respectively $(P<0.01)$.

Although with some exceptions, probably related to the low sample sizes and broad confidence intervals, some general trends could be extracted from the different indices used to characterize the growth of the species (Table 2). The instantaneous daily growth rate (G) decreased with age when both growth-in-weight and growth-in-length were considered. However, the behaviour of the daily growth rate index (DGR) was not so clear because it increased with age in all cases except for the growth-in-length of males. Males younger than $180 \mathrm{~d}$ old had greater growth rates (both in G and DGR) than females, but from this age their values became in general clearly lower than those of females. The gonad development, indicated by both the gonadosomatic (GSI) and nidamental gland (NGI) indices, increased with age while the digestive gland index (DGI) decreased. This probably reflects increased investment in reproduction, at the expense of somatic growth, with age.

At ages younger than $210 \mathrm{~d}$ old, growth rates (both $\mathrm{G}$ and DGR) of squids from north-west Africa were in general higher than those from the Mediterranean Sea. However, at older ages they have clearly lower values than the Mediterranean populations. These differences in growth rates are reflected in the mean size of squids from both areas, since sampled west Saharan populations had greater sizes than the Mediterranean ones. However, taking into account the extrapolated data from northwest Africa at ages older than $270 \mathrm{~d}$, the corresponding sizes are significantly lower than those obtained in the sampled Mediterranean squid.

\section{Maturation and hatching time}

The youngest mature male and female were 222 (222 mm ML, $365.8 \mathrm{~g}$ TW) and 257 (318 mm ML, $1049 \mathrm{~g}$ TW) days old, respectively. The age at which $50 \%$ of individuals were mature was 245 and 300 days for males and females, respectively. These results showed that females mature more than a month older than males. West
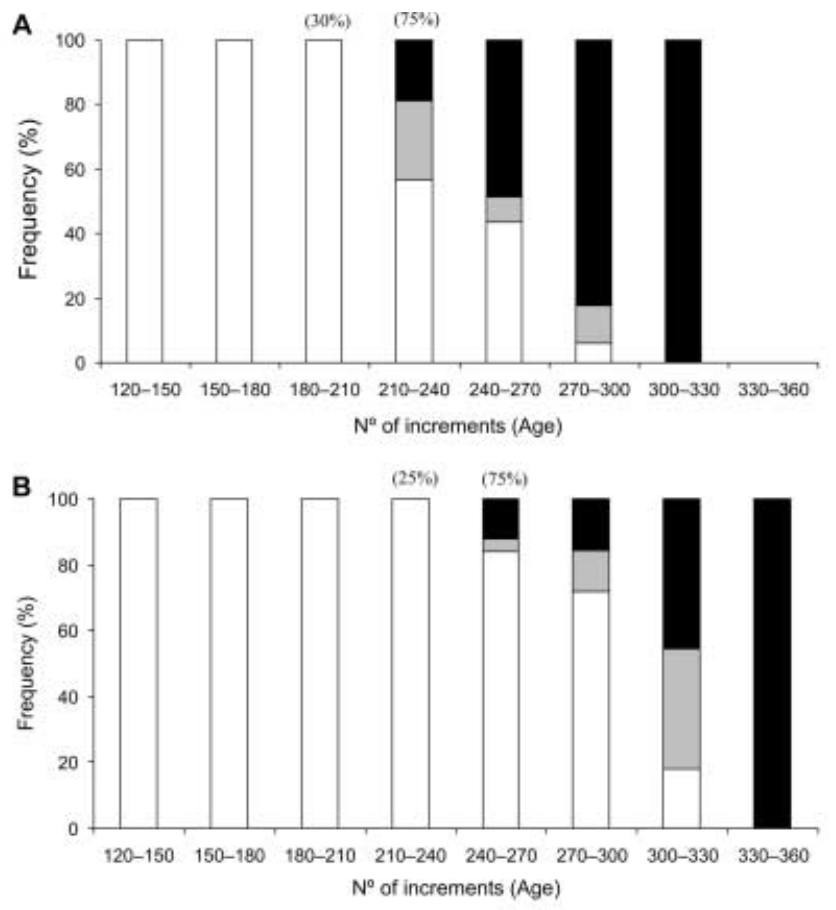

Figure 1. Evolution of the three different maturity stages throughout 30 days age intervals in males (A) and females (B) of Todarodes sagittatus from the western Mediterranean Sea. (White, immature; grey, maturing; and black, mature). The percentage of mature individuals in west Sahara populations (Arkhipkin et al., 1999) are shown in parentheses for comparisons. 


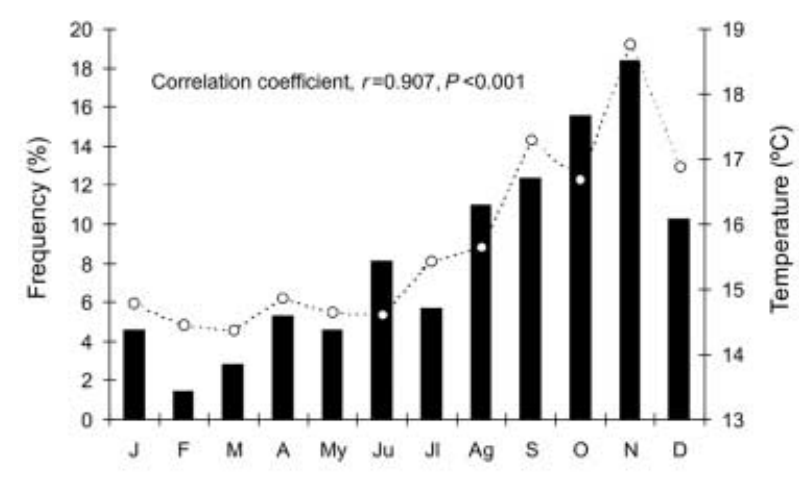

Figure 2. Hatching dates of Todarodes sagittatus and temperature at $50 \mathrm{~m}$ depth in the study area from the western Mediterranean. The correlation coefficient $(r)$ between temperature and number of hatchlings is also shown.

Saharan squid reach maturity at younger ages than Mediterranean ones, because $75 \%$ of males and females were mature at ages of 220-230 d and 250-270 d respectively (Figure 1).

Back-calculated hatching dates showed that although hatching occurred throughout the year, it was maximum between August-December with a clear peak in November (Figure 2). When hatching was lowest (January-July), temperature at $50 \mathrm{~m}$ depth was rather constant at $14-15^{\circ} \mathrm{C}$ but increased to $16-19^{\circ} \mathrm{C}$ during the maximum of hatching. The correlation coefficient between temperature and number of hatchlings was highly significant $(r=0.907, P<0.001)$.

\section{DISCUSSION}

Age determination becomes a reliable element of the scientific fisheries' assessment when it is accurate and precise. In age determination studies of fish it is common practice to determine the reproducibility of the procedure and to determine the periodicity in increment formation. This is not the case in cephalopods, where most studies do not validate the periodicity of growth increments (Villanueva, 1992; Arkhipkin et al., 1999) and daily formation is assumed based on the results obtained in a few studies where such periodicity was experimentally tested (Hurley et al., 1985; Nakamura \& Sakurai, 1991). In the present paper, the hypothesis of daily increment formation in Todarodes sagittatus statoliths was indirectly validated comparing the mean number of increments corresponding to the modal size from consecutive months with the number of days elapsed between modes. This result was further supported by the coincidence of the peak of hatching (November, see below) and the maturation period (September-December; Quetglas et al., 1998).

Growth rate comparisons between north-west African (Arkhipkin et al., 1999) and Mediterranean populations showed that juveniles (younger than $210 \mathrm{~d}$ old) from the southern region grow faster than those caught in northern waters. However, at older ages the pattern is inverted since Mediterranean individuals have higher growth rates than the west Sahara ones. As a consequence of this differential growth, southern populations achieved greater sizes than northern ones at middle ages (up to $270 \mathrm{~d}$ old). Data from north-west African squid older than $270 \mathrm{~d}$ are only based on extrapolations but, if they are considered, it is shown that Mediterranean squid would have greater sizes than those from west Sahara. Differences also appear in sexual maturation because north African populations mature earlier than Mediterranean ones $70 \%$ of females older than $250 \mathrm{~d}$ are mature in the first region, whereas $50 \%$ of them are mature at $300 \mathrm{~d}$ in the second one). All these results suggest that due to higher growth rates in juveniles, southern populations reach maturity and consequently decrease somatic growth at younger ages and smaller sizes than northern squid, which attain larger sizes as a result of maintaining fast growth and delaying maturation (Lee's phenomenon). Data from North Atlantic populations (Rosenberg et al., 1980; Wiborg \& Beck, 1984; Lordan et al., 2001) agree with this pattern of larger sizes and delayed maturation with increasing latitude, but nothing can be said about growth rates because in these studies they were calculated for the population as a whole. Differences are rather important since size at maturity and mean sizes from North Atlantic squid are 100-150 mm greater than those from west Sahara. Lifespan should also be taken into account because, whereas in north-west Africa (Arkhipkin et al., 1999) and in the Mediterranean (present work) it lasts only a year, North Atlantic squid were found to live longer (Rosenberg et al., 1980; Wiborg \& Gjosaeter, 1981; Lordan et al., 2001).

The existence of a great number of factors affecting growth (mainly temperature, food intake and age) makes it difficult to find a satisfactory explanation for the variations observed in growth rates. This difficulty is emphasized in cephalopods, which due to fast growth and short lifespan are greatly affected by environmental fluctuations. In fact, Villanueva (1992) found that T. angolensis showed differential growth rates owing to environmental changes in the Benguela upwelling system. One of the main factors affecting growth is temperature but its importance on T. sagittatus would be minimized because, apart from living in a wide depth range both in the Mediterranean and in west Sahara, the squid makes diel vertical movements and also ontogenetic migrations to deeper waters. Thus, growth rates of larvae and juveniles would be more influenced by temperature than those of adults because they are always found in shallower waters, where temperature is higher. In fact, Shimko (1989) found that larvae in the North Atlantic were distributed over the thermocline and revealed an increase of larval size with depth. This could explain why juveniles from north-west Africa have greater growth rates than those from the Mediterranean, since temperatures are higher in the first area. Lower growth rates in the Mediterranean than off north-west Africa were also found in the ommastrephid Illex coindetii (Arkhipkin, 1996).

Hatching of T. sagittatus in the Mediterranean Sea occurred throughout the year but with a clear peak in November. North-west African populations showed the same pattern, although the peak was there in February (Arkhipkin et al., 1999). Hatching in the North Atlantic was not as protracted as in southern areas but two or three peaks occurring in winter (December-January), spring (May-June) and autumn (September-October) were found (Rosenberg et al., 1980; Shimko, 1984; Lordan et al., 2001). Spawning in the North Atlantic 
takes place around the Azores' seamounts from where the larvae, which were mainly found between 50-150 m depth with temperatures of $13-20^{\circ} \mathrm{G}$, migrates periodically in north-east and south-east directions (Shimko, 1989). Available data indicate that hatchlings of other Todarodes species are mainly found between $25-50 \mathrm{~m}$ depth and temperature range of $15-22^{\circ} \mathrm{C}$ (Watanabe, 1965; Sakurai et al., 1996). In agreement with this, highly significant correlations were found between temperature at $50 \mathrm{~m}$ depth and the number of hatchlings in the present study. When hatching was highest (August-December) temperature increased to $16-19^{\circ} \mathrm{C}$, whereas it remained rather constant at $14-15^{\circ} \mathrm{C}$ during the rest of the year. Unfortunately, we did not find temperature data from west Sahara in the literature which allow us to infer its influence on hatching. Concerning North Atlantic squid, although Shimko (1989) determined the depth and temperature where hatchlings inhabit, the existence of more than one peak of hatching in such cold waters remains unexplained.

This study was carried out within the framework of the project 'Discards of the western Mediterranean trawl fleets' (Contract ref. DG-XIV, MED/94/027). We wish to express our gratitude to the crew of the trawlers 'Illa del Sol', 'Nou Capdepera', 'Portocolom' and 'Rafael Irene' for their kindness during the on-board sampling. Dr Fernández de Puelles (IEO-Centre Oceanogràtic de Balears) kindly offered the temperature data at $50 \mathrm{~m}$ depth (Project 1007-IEO). The first author is indebted to Dr Villanueva (Institut de Ciències del Mar, CMIMA-Barcelona, Spain), who showed him the techniques of statolith analysis and critically revised a first version of this manuscript. Thanks also to J. Moranta (CSIC/UIB-IMEDEA) for his useful comments and to $\mathrm{C}$. Ballester for the English version.

\section{REFERENCES}

Arkhipkin, A.I., 1996. Geographical variation in growth and maturation of the squid Illex coindetii (Oegopsida, Ommastrephidae) off the north-west African coast. Fournal of the Marine Biological Association of the United Kingdom, 76, 1091-1106.

Arkhipkin, A.I. \& Golub, A., 2000. Aberrant structure of the statolith postnuclear zone in the squid Todarodes sagittatus (Cephalopoda: Ommastrephidae). Fournal of the Marine Biological Association of the United Kingdom, 80, 183-184.

Arkhipkin, A., Laptikhovsky, V. \& Golub, A., 1999. Population structure and growth of the squid Todarodes sagittatus (Cephalopoda: Ommastrephidae) in north-west African waters. Fournal of the Marine Biological Association of the United Kingdom, 79, 467-477.

Borges, T.C. \& Wallace, J.C., 1993. Some aspects of the fishery biology of the ommastrephid squid Todarodes sagittatus (Lamarck, 1798) from the northeast Atlantic. In Recent advances in fisheries biology (ed. T. Okutani et al.), pp. 25-36. Tokyo: Tokai University Press.

Chang, W.Y.B., 1982. A statistical method for evaluating the reproducibility of age determination. Canadian Fournal of Fisheries and Aquatic Sciences, 39, 1208-1210.

Forsythe, J.W. \& Van Heukelem, W.F., 1987. Growth. In Cephalopod life cycles (ed. P.R. Boyle), pp. 135-156. London: Academic Press.

Hurley, G.V., Odense, P., O’Dor, R.K. \& Dawe, E.G., 1985. Strontium labelling for verifying daily growth increments in the statoliths of the short-finned squid (Illex illecebrosus). Canadian Fournal of Fisheries and Aquatic Sciences, 42, 380-383.
Jonsson, E., 1980. Biological studies on squid, Todarodes sagittatus in Icelandic waters during the autumn 1979 with notes on its distribution and migration. Hafrannsóknarstofnun Fjölrit, 7, 1-14.

Laine, A.O., Momot, W.T. \& Ryan, P.A., 1991. Accuracy of using scales and cleithra for ageing northern pike from an oligotrophic Ontario lake. North American Fournal of Fisheries Management, 11, 220-225.

Lipinski, M., Dawe, E. \& Natsuraki, Y., 1991. Introduction. In Squid age determination using statoliths. Proceedings of the International Workshop held in the Istituto di Tecnologia della Pesca e del Pescato (ed. P. Jereb et al.), pp. 77-81. Special Publication.

Lordan, C., Collins, M.A., Key, L.N. \& Browne, E.D., 2001. The biology of the ommastrephid squid, Todarodes sagittatus, in the north-east Atlantic. Journal of the Marine Biological Association of the United Kingdom, 81, 299-306.

Nakamura, Y. \& Sakurai, Y., 1991. Validation of daily growth increments in statoliths of Japanese common squid Todarodes pacificus. Nippon Suisan Gakkaishi, 57, 2007-2011.

Quetglas, A., Alemany, F., Carbonell, A., Merella, P. \& Sánchez, P., 1998. Some aspects of the biology of Todarodes sagittatus (Cephalopoda: Ommastrephidae) from the Balearic Sea (western Mediterranean). Scientia Marina, 62, 73-82.

Rosenberg, A.A., Wiborg K.F. \& Bech, I.M., 1980. Growth of Todarodes sagittatus (Lamarck) (Cephalopoda, Ommastrephidae) from the Northeast Atlantic, based on counts of statolith growth rings. Sarsia, 66, 53-57.

Sakurai, Y., Bower, J.R., Nakamura, Y., Yamamoto, S. \& Watanabe, K., 1996. Effect of temperature on development and survival of Todarodes pacificus embryos and paralarvae. American Malacological Bulletin, 13, 89-95.

Shimko, B.P., 1984. Ageing and biological peculiarities of Todarodes sagittatus (Lamarck). International Council for the Exploration of the Sea (CM Papers and Reports), CM 1984/K:12, 12 pp.

Shimko, B.P., 1989. Biology and peculiarities of the squid Todarodes sagittatus (Lamarck) distribution at early life stages. International Council for the Exploration of the Sea (CM Papers and Reports), CM 1989/K:17, 12 pp.

Sokal, R.R. \& Rohlf, F.J., 1995. Biometry: the principles and practice of statistics in biological research. New York: W.H. Freeman \& Company.

Villanueva, R., 1992. Interannual growth differences in the oceanic squid Todarodes angolensis Adam in the northern Benguela upwelling system, based on statolith growth increment analysis. Fournal of Experimental Marine Biology and Ecology, 159, 157-177.

Watanabe, T., 1965. Ecological distribution of rhynchoteution larva of common squid, Todarodes pacificus Steenstrup, in the southeastern waters off Japan during the winters, 1959-1962. Bulletin of Tokai Regional Fisheries Research Laboratory, 43, 1-12.

Wiborg, K.F., 1980. The squid Todarodes sagittatus (Lamarck). Immigration and occurrence at the Norwegian coast and adjacent ocean areas from the autumn 1979 to the spring 1980. Fisken Havet, 3, 13-27.

Wiborg, K.F. \& Beck, I.M., 1984. The squid Todarodes sagittatus (Lamarck). Investigations in Norwegian coastal and bank waters, July 1983-January 1984, and west of the British Isles, March-April 1984. International Council for the Exploration of the Sea (CM Papers and Reports), CM 1984/K:20, 14 pp.

Wiborg, K.F. \& Gjosaeter, J., 1981. The squid Todarodes sagittatus (Lamarck). Distribution and biology in Northern waters, April 1980-April 1981. International Council for the Exploration of the Sea (CM Papers and Reports), GM 1981/K:14, 18 pp.

Wiborg, K.F., Gjosaeter, J., Beck, I.M. \& Fossum, P., 1982. The squid Todarodes sagittatus (Lamarck). Distribution and biology in Northern waters, August 1981-April 1982. International Council for the Exploration of the Sea (CM Papers and Reports), CM 1982/K:30, 17 pp.

Submitted 9 Fanuary 2003. Accepted 12 February 2004. 